Research Article

\title{
Complementary and alternative medicine: practice and perspective of allopathic doctors at a tertiary care hospital
}

\author{
Dharani Sundarmurthy*, Vijayalakshmi Devarashetty, Narayana Reddy S.
}

\begin{abstract}
Department of Pharmacology, Bangalore Medical College and Research Institute, Fort Road, Bengaluru-560002, India
\end{abstract}

Received: 30 June 2016 Accepted: 05 August 2016

\section{*Correspondence to:}

Dr. Dharani Sundarmurthy, Email: dr.dharanisundar@ gmail.com

Copyright: (C) the author(s), publisher and licensee Medip Academy. This is an openaccess article distributed under the terms of the Creative Commons Attribution NonCommercial License, which permits unrestricted noncommercial use, distribution, and reproduction in any medium, provided the original work is properly cited.

\begin{abstract}
Background: Complementary and alternative medicine (CAM) has been defined as a group of diverse healthcare systems, not considered to be a part of conventional (allopathic) medicine. Approximately $80 \%$ of general population use traditional medicines (WHO). Thus, patients using CAM and its associated adverse effects may be encountered in practice of modern medicine. Hence it is necessary to assess the knowledge, attitude and practices of CAM among health care professionals (HCPs).

Methods: After obtaining IEC approval, the cross-sectional study was conducted in doctors at Bangalore Medical College and its attached hospitals. 200 doctors who gave informed consent were included in the study.

Results: $61.5 \%$ of the HCPs were aware that CAM includes AYUSH. 53\% of the HCPs used CAM for self, especially for respiratory disorders $(28.3 \%)$ and chronic painful conditions $(21.6 \%)$. The common adverse effects attributed to use of CAM among patients which required consultation of the HCPs were hepatic $(42.5 \%)$ and renal impairment $(32.5 \%)$, allergy $(10 \%)$, relapse $(10 \%)$, and metal intoxication (5\%). 71\% didn't prefer suggesting CAM for patients. $70 \%$ opined that CAM therapies be subjected to clinical trials.

Conclusions: HCPs had used CAM therapy for self at least once especially for respiratory disorders and chronic painful conditions. However majority of the HCPs didn't prefer suggesting CAM to patients and as many as $70 \%$ of the HCPs insisted that CAM therapies be subjected to scientific evaluation including clinical trials in view of patient safety before integrating them with conventional medicine.
\end{abstract}

Keywords: CAM, Allopathic doctors, Ayurveda, Yoga, Attitude, Practice

\section{INTRODUCTION}

Complementary and alternative medicine (CAM) is defined as a group of diverse medical and healthcare systems, practices and products that are presently not considered to be a part of conventional allopathic medicine. CAM encompasses practices such as yoga, meditation, ayurveda, traditional Chinese medicine, homeopathy, naturopathy and many other such systems which are intended to facilitate healing of both body and mind. ${ }^{1}$ Countries like India, China, Korea, Japan, and Vietnam have all developed their own unique versions of traditional medicines apart from the above mentioned systems. $^{2}$
A vast majority of medical systems such as Ayurveda, Unani, Siddha, Yoga, Homeopathy and Naturopathy have prospered in India over years. European Medicine became the official health care system in India under the British Rule, and this relegated Indian systems of medicine. In 1995, Government of India took an initiative to establish department of Indian systems of medicine and homeopathy (ISM and $\mathrm{H}$ ) which was subsequently renamed as department of Ayurveda, Yoga, Unani, Siddha and Homeopathy (AYUSH) in 2003. . $^{3,4}$

The global prevalence of CAM usage ranges from $9.8 \%$ to $76 \% .^{5}$ CAM use both in health and disease is a universal phenomenon in developed and developing countries alike. ${ }^{6-8}$ The propensity for CAM use among patients is most evident in areas such as, oncology, 
chronic illnesses, where in comfort care is the priority or because of dissatisfaction with some aspects of conventional health care, fear of adverse effects, accessibility, affordability of allopathic medicines, perceived effectiveness of CAM and/or influence by the family/friends. ${ }^{9-12}$

In 2013, WHO estimated that in developing countries including India, wherein majority of the population lives in rural areas, native traditional healers are often the sole health care providers. In addition to this, some studies have uncovered the potential reasons for CAM use among Indians such as, high prevalence of chronic illnesses like diabetes mellitus, hypertension, coronary artery disease, rheumatoid arthritis and strong cultural belief/philosophical congruence, as well as an increasing number of advertisements about CAM. ${ }^{10,11,13-15}$ According to a recent review, about $15 \%$ of patients concomitantly use CAM which contributes to adverse herb-drug interactions in $40 \%$ of the patients to which the treating physician is often oblivious. ${ }^{16}$

Popular belief is that herbal drugs are of natural origin and hence safer, but this seems to be a dangerous oversimplification. A study conducted by Robert B et al, revealed that, about one fifth of both US and Indian manufactured Ayurveda medicines contain detectable lead, mercury, or arsenic which exceeded one or more standards for acceptable daily intake of toxic metals. Under these circumstances, injudicious use of CAM is likely to result in herb-drug interactions and adverse health outcomes, which could possibly be avoided by testing them for efficacy and safety in clinical trials. However, because of the numerous problems in methodology and logistics such as patent issues for herbal products, lack of research culture and expertise in alternative medicine, testing of CAM medicines is still in infancy. ${ }^{17,18}$

Currently, disease management strategies of allopathic system including pharmacological and nonpharmacological treatments are based on sound scientific knowledge. Although cross-practice is not legalised it is quite rampant in India. ${ }^{19}$ The primary duty of a Health care professional (HCP) is not only to work towards relief of an ailment but also to make sure that the treatment causes no overt harm. Routine inquiry of patients about CAM use by the HCPs may improve and enhance their care by avoiding potentially harmful drug interactions. $^{20}$ Their attitudes and beliefs may have a strong impact on the way they ultimately practice medicine. Hence, we aimed to assess the practice, perception, and knowledge of CAM among practicing physicians.

\section{METHODS}

After obtaining approval from the Institutional Ethics Committee, 232 HCPs working at Bangalore Medical College and its attached hospitals were approached. 200
HCPs, voluntarily willing to participate in the study were given a structured study proforma, consisting of sociodemographic details and a semi-structured questionnaire to be filled. For the purpose of this study, HCPs mean, only allopathic doctors. The questionnaire consisted of total 17 questions intended to assess the practice, perception and knowledge of the HCPs on CAM use for self and in their patients. The study was conducted between October 2015 to December 2015 and written informed consent was obtained from all the participants.

\section{Statistical analysis}

The data obtained in the form of completed questionnaires was categorised and analysed. Continuous variables were presented as mean \pm standard deviation (SD), and categorical variables were presented as percentages. Chi square test was done to compare the categorical variables and $\mathrm{p}$ value $<0.05$ was considered to be statistically significant.

\section{RESULTS}

232 HCPs were approached, of which 200 HCPs consented to participate in the study. The response rate was $86 \%$.

The Mean age of HCPs included in the study was $35.4 \pm$ 7.6 years with $43.5 \%$ and $56.5 \%$ being males and females respectively [Table 1].

Table 1: Demographics.

\begin{tabular}{|ll|}
\hline Variables & $\mathbf{n}=\mathbf{2 0 0}$ \\
\hline Age $($ Mean \pm SD) & $35.4 \pm 7.6$ years \\
\hline \multirow{2}{*}{ Sex } & Males $-87(43.5 \%)$ \\
\cline { 2 - 2 } & Females $-113(56.5 \%)$ \\
\hline
\end{tabular}

Females are more likely to use CAM as compared to males which were statistically significant. $\left(\chi^{2}=5.37\right.$, $\mathrm{p}=0.020$ ) [Table 2].

Table 2: Gender specific use of CAM.

\begin{tabular}{|c|c|c|c|}
\hline$n=200$ & $\begin{array}{l}\text { CAM } \\
\text { users }\end{array}$ & $\begin{array}{l}\text { CAM non } \\
\text { users }\end{array}$ & Chi-square \\
\hline Females & 68 & 45 & \multirow{2}{*}{$\begin{array}{l}\chi 2=5.37, \mathrm{df}=1 \\
\mathrm{p}<0.05\end{array}$} \\
\hline Males & 38 & 49 & \\
\hline
\end{tabular}

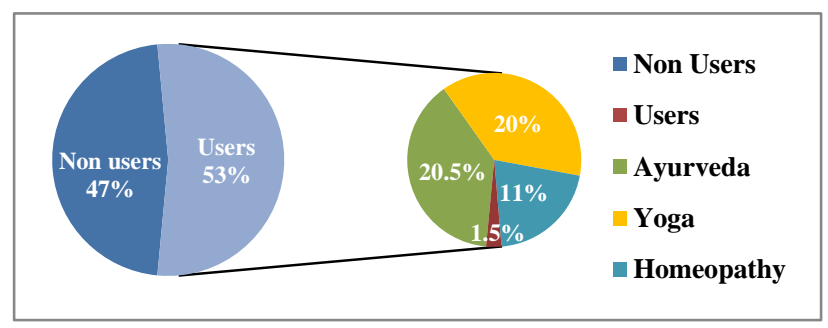

Figure 1: CAM use for self. 
One hundred and six HCPs (53\%) had used CAM for self at least once. Ayurveda (20.5\%) was the most commonly used CAM, followed by yoga (20\%), homeopathy (11\%) and siddha (1.5\%) (Figure 1).

Table 3: Conditions/purpose of using CAM for self.

\begin{tabular}{|c|c|c|}
\hline $\begin{array}{l}\text { Conditions/ } \\
\text { purpose }\end{array}$ & Percentage & Specific problems \\
\hline $\begin{array}{l}\text { Respiratory } \\
\text { ailments }\end{array}$ & $28.30 \%$ & $\begin{array}{l}\text { Allergic rhinitis, } \\
\text { asthma, cough, cold, } \\
\text { wheeze, sinusitis }\end{array}$ \\
\hline $\begin{array}{l}\text { Pain and } \\
\text { fever relief }\end{array}$ & $21.60 \%$ & $\begin{array}{l}\text { Low back pain, knee } \\
\text { pain, Rheumatoid } \\
\text { arthritis, fever, } \\
\text { migraine }\end{array}$ \\
\hline Fitness & $17 \%$ & Lose weight \\
\hline $\begin{array}{l}\text { Skin/hair } \\
\text { conditions }\end{array}$ & $8.40 \%$ & $\begin{array}{l}\text { Acne, wart, alopecia, } \\
\text { psoriasis, greying hair }\end{array}$ \\
\hline Stress & $7.50 \%$ & $\begin{array}{l}\text { Relieve tension, stress, } \\
\text { anxiety }\end{array}$ \\
\hline Hepatitis & $3.60 \%$ & Post hepatitis \\
\hline Others & $13.70 \%$ & $\begin{array}{l}\text { Gastritis, UTI, renal } \\
\text { stones, menstrual } \\
\text { problems, pregnancy }\end{array}$ \\
\hline
\end{tabular}

Respiratory ailments $(28.3 \%)$, followed by pain and fever relief $(21.6 \%)$ and to maintain fitness $(17 \%)$ were the most common conditions cited (Table 3). Very few $(6.6 \%)$ reported having experienced adverse effects.

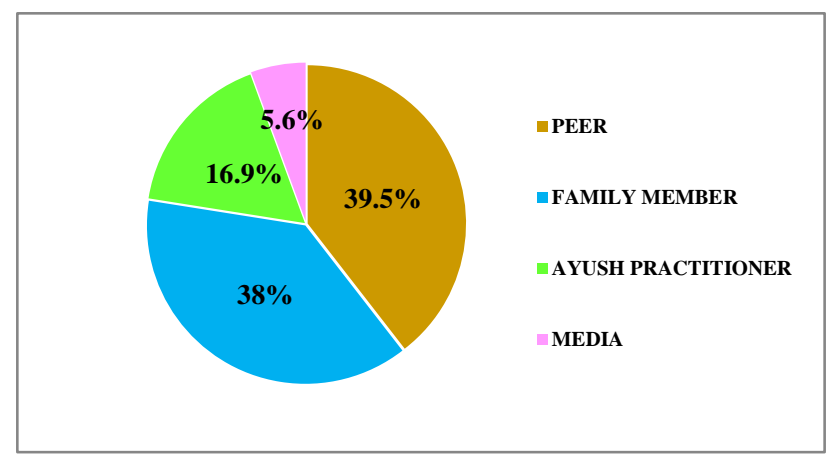

Figure 2: Influencing factors for CAM use.

CAM use for self in majority of HCPs (53\%) was influenced mainly by peer group $(39.5 \%)$, followed by family members (38\%), AYUSH practioner (16.9\%) and media (5.6\%) (Figure 2).

27.5\% of the HCPs suggested Yoga and Ayurveda to their patients. Most common conditions for which it was suggested were anxiety, depression, life style diseases like diabetes and hypertension, bronchial asthma, allergy, arthritis, backache, hepatitis, renal calculi and pregnancy (Figure 3).

Nearly $46 \%$ of HCPs routinely inquired their patients about CAM use. The common adverse effects resulting from CAM use which required consultation of the HCPs were hepatic impairment $(42.5 \%)$, renal impairment $(32.5 \%)$, allergic reactions $(10 \%)$, relapse of the disease $(10 \%)$ and metal intoxication (5\%) (Figure 4).

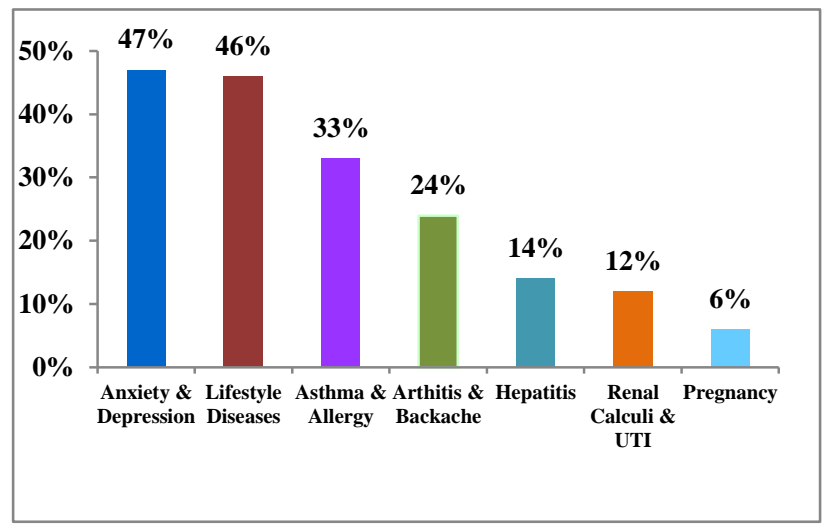

Figure 3: Conditions for which CAM therapy suggested to patients.

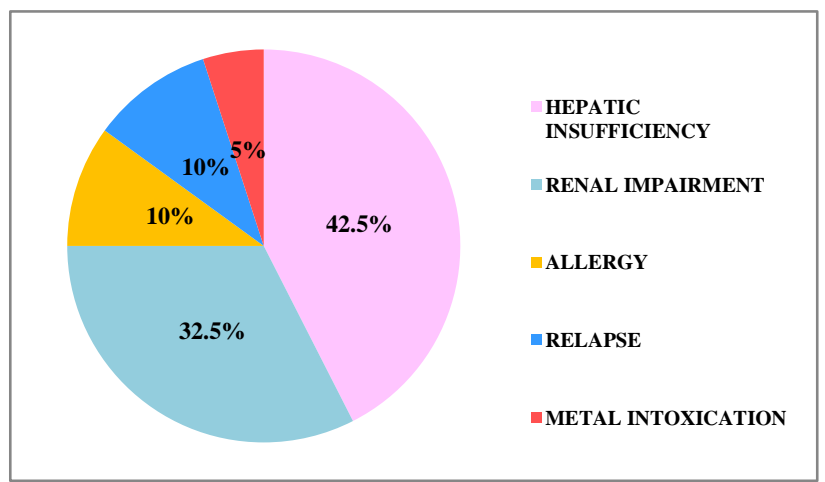

Figure 4: Side effects encountered in patients.

Approximately $62 \%$ of the HCPs were aware that AYUSH (Ayurveda, yoga, unani, siddha and homeopathy) comes under the purview of CAM. $70 \%$ of the HCPs opined that, medicines or therapies under AYUSH must be subjected to clinical trials before they can be used in an integrated manner (Figure 5).

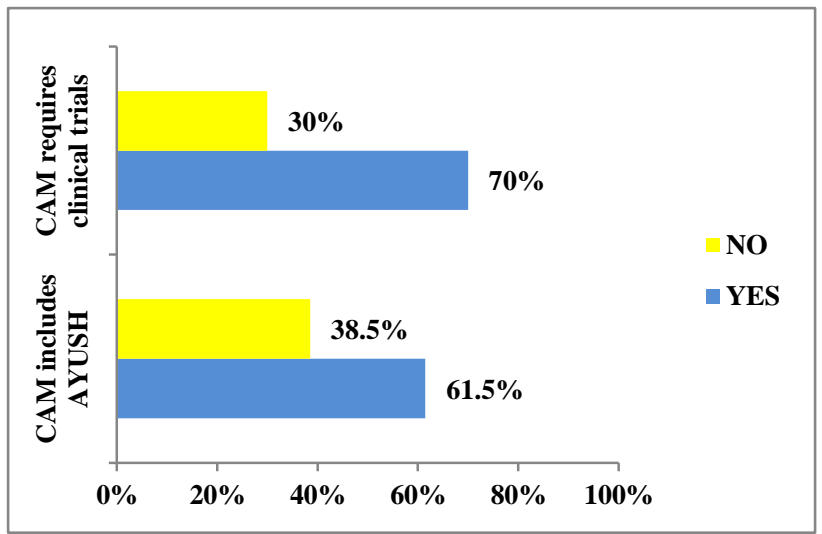

Figure 5: Knowledge. 
$71 \%$ of the HCPs didn't prefer suggesting CAM to their patients, and the most common reason cited being deficit of literature on herb-drug interactions (30\%), better allopathic alternatives $(27.3 \%)$, and inadequate scientific evaluation (20.2\%) (Table 4).

Table 4: Reasons for not preferring CAM.

\begin{tabular}{|ll|}
\hline Reasons & Percentage \\
\hline $\begin{array}{l}\text { Deficit of literature on herb-drug } \\
\text { interactions }\end{array}$ & $30 \%$ \\
\hline Better allopathic alternatives & $27.3 \%$ \\
\hline Inadequate scientific evaluation & $20.2 \%$ \\
\hline Cross practice not legalised & $13.6 \%$ \\
\hline Neither effective nor safe & $8.9 \%$ \\
\hline
\end{tabular}

Approximately one-third of the HCPs perceived that CAM is beneficial in chronic diseases. However, 70.5\% of them were indecisive about the safety of herbs/compounds/substances/preparations used in AYUSH in pregnant or lactating women (Figure 6).

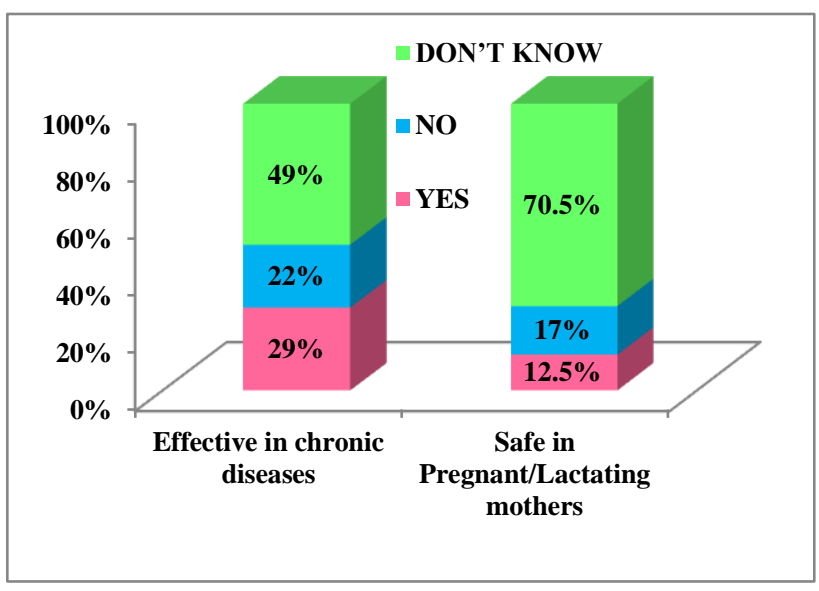

Figure 6: Perception.

\section{DISCUSSION}

India is the birth place of many traditional health care systems like ayurveda, yoga and siddha, laid their foundation of healing based on natural resources and spiritual techniques. In India people are influenced by traditions, culture, beliefs, and the arena they touch upon also includes "Health related issues". Often the use of traditional medicine and/or home remedies go hand in hand with conventional/allopathic medicines. There has been a steep increase in CAM use over years, in developing and developed countries alike. The major reasons being slick marketing, non-stringent regulations, scientific illiteracy, gullible media advertisements, vulnerable public and limitations of the mainstream medicine. Hence, its use seems to be omnipresent. Thus it is imperative that awareness, attitude and practice of CAM needs to be measured, and hence this study.
The respondents in this study were $43.5 \%$ and $56.5 \%$ of males and females respectively with mean age of 35.4 years which is in line with a study conducted by Kunnoor NS at a tertiary care hospital in Bengaluru. ${ }^{20}$ Thus, female HCPs were more likely to use CAM than male HCPs which was statistically significant. A similar trend was also evident in the previous studies conducted in United states and India where females were more likely to believe in CAM than males. ${ }^{21,22}$

$53 \%$ of the HCPs used CAM at least once, which is comparable $(58 \%)$ to a study conducted by Vandana Roy et al. in New Delhi, India. They also reported that, homeopathy was the most commonly used CAM followed by ayurveda, yoga and others. ${ }^{22}$ However this study showed that, ayurveda and yoga were used in equal proportion (20.5\% and $20 \%$ respectively), followed by homeopathy and siddha.

Commonest causes for which CAM was used for self by the HCPs were chronic diseases like bronchial asthma, allergic rhinitis, back pain, rheumatoid arthritis, osteoarthritis, migraine and to lose weight which concurs with earlier studies that measured CAM utilization among allopathic doctors both in developing and developed countries. $^{22,23}$ In a study conducted by Suchitha et al., in Mumbai, use of CAM among HCPs along with conventional medicines was common for chronic ailments. ${ }^{19}$ Other studies have reported similar reason for utilization of CAM among patients also. ${ }^{10,14,15,24}$ Hence utilization of CAM seems to be a universal phenomenon. CAM use was mainly influenced by friends and family members and the same is revealed by a study conducted by Zaman et al. done at All India Institute of Medical Sciences, New Delhi. ${ }^{24}$

Although $71 \%$ of the HCPs didn't prefer suggesting CAM to their patients, $29 \%$ perceived that CAM was effective in chronic conditions and $27.5 \%$ suggested CAM therapies to their patients for the same. The study conducted by Kunnoor NS et al., in Bangalore, India also reported that $27.1 \%$ of the physicians recommended CAM to their patients, especially yoga and meditation. ${ }^{20}$ It is evident from the current study that, the practice of CAM by HCPs is in line with their belief ( $27 \%$ vs $29 \%$ respectively). It was also noted that the HCPs suggesting CAM therapies to their patients were among the $53 \%$ who had used CAM for self. A study conducted in UK by Lewith et al, also found that, those who use CAM personally are more likely to refer their patients to CAM. $^{23}$

Inquiry about CAM use among patients was routinely done by $46 \%$ HCPs, which is higher than in a study reported by Roy $\mathrm{V}$, wherein only $37 \%$ inquired about CAM use. ${ }^{22}$ CAM is perceived as a safer option by most people. Concomitant use of CAM and conventional treatment, if unsolicited could lead to potentially dangerous drug interactions, unforeseen side effects, and organ toxicities which matches with similar findings in 
this study where in, hepatic $(42.5 \%)$ and renal $(32.5 \%)$ impairments were the commonest side effects experienced by the patients with history of CAM use for which they consulted allopathic doctors. ${ }^{16,19,21,25}$ At the other end of the spectrum, disclosure rates by patients regarding CAM use despite inquiry by doctors are low $(<40 \%)$ as shown by the study conducted by Eisenberg et al in the US. ${ }^{26}$ Another study also reported that nearly $60 \%$ of patients with advanced breast cancer disclosed details of CAM use when the herbal medicine was ingested. The disclosure rates were low in patients who used homeopathy. ${ }^{27}$ Though in this study we didn't interview patients to elicit the disclosure rates, extensive promotion and perception of CAM as safe among general population, coupled with low disclosure rates as described in different studies, may be contributing to vital organ toxicity especially when CAM is used concomitantly with conventional therapy.

$71 \%$ of the HCPs in this study didn't prefer suggesting CAM to their patients. The reasons cited were, deficit of literature on herb-drug interactions, better allopathic alternatives, inadequate scientific evaluation, and lack of clarity with respect to their efficacy in chronic conditions. In addition, most were unsure of its safety in pregnancy and lactation. As many as $70 \%$ of the HCPs insisted that clinical trials should be conducted in order to scientifically establish their role in betterment of health and disease which is also noted in other studies. ${ }^{6,28}$

Though integrative medicine is talked about much nowadays in scientific community, the fundamental principles based on which each system of medicine treats a patient is entirely different. For instance, in Ayurveda the pathological basis and treatment of any disease is based on three different doshas i.e., vata, pitta, and kapha which is incomprehensible to the mainstream allopathic practioners. $^{29}$ In other parts of the world, governments are not only interested in herbal medicines, but are also formulating and implementing a robust regulatory framework in order to integrate CAM into mainstream practice. ${ }^{13}$ Govt. of India has similar inclination, however, integrating CAM with allopathic medicine can be tricky in many aspects of patient care especially with respect to safety. Before proceeding with such concept, key issues like scientific validation of the compounds and techniques, establishment of pharmacopeal standards for formulations, laying down GMP guidelines, standardization of quality control of drugs used in CAM and finally subjecting them to clinical trials seems to be need of the hour as this is an era of evidence based medicine.

\section{CONCLUSION}

Utilization of CAM therapy for self by the HCPs at least once is quite prevalent, especially for respiratory disorders and chronic painful conditions. Those who perceived CAM as effective in chronic conditions, suggested the same to their patients. However majority of the HCPs $(71 \%)$ didn't prefer CAM as, they were not convinced of their efficacy and safety in chronic conditions and in vulnerable populations although they are widely being promoted. $70 \%$ of the HCPs insisted that CAM therapies be subjected to clinical trials. Though the traditional systems of medicine should be preserved and nurtured, modern day practice of medicine stands on the strong pillars of sound scientific evaluation. Hence integrating CAM with conventional medicine would require the same standards to be fulfilled by the former for the benefit of the patients.

\section{ACKNOWLEDGEMENTS}

We hereby extend our gratitude to doctors working in Bangalore Medical College and Research Institute, for participating in this study.

Funding: No funding sources

Conflict of interest: None declared

Ethical approval: The study was approved by the Institutional Ethics Committee

\section{REFERENCES}

1. CAM basics: Updated 25 May 2012. Available at https://nccih.nih.gov/sites/nccam.nih.gov/files/D347_ 05-25-2012.pdf.

2. Tabish SA. Complementary and alternative healthcare: is it evidence-based? International Journal of Health Sciences. 2008;2(1):V-IX.

3. Roy V. Time to sensitize medical graduates to the Indian Systems of Medicine and Homeopathy Editorial. Indian J Pharmacol. 2015;47:1.

4. Planning Commission, Government of India. Indian systems of medicine and homeopathy. Available at http://www.Planning commission.gov.in/plans/mta/mta9702/mtach19.

5. Harris PE, Cooper KL, Relton C, Thomas KJ. Prevalence of complementary and alternative medicine (CAM) use by the general population: a systematic review and update. Int $\mathbf{J}$ Clin Pract. 2012;66:924-39.

6. Kinsel JF, Straus SE. Complementary and alternative therapeutics: Rigorous research is needed to support claims. Annu Rev Pharmacol Toxicol. 2003;43:46384.

7. Sharma R, Kapoor B, Verma U. Drug utilization pattern during pregnancy in Northern India. Indian $\mathrm{J}$ Med Sci. 2006;60:277-87.

8. Verma U, Sharma R, Gupta P, Gupta S, Kapoor B. Allopathic versus ayurvedic practices in tertiary care institutes of urban North India. Indian J Pharmacol. 2007;39:52-4.

9. Gupta M, Shafiq N, Kumari S, Pandhi P. Patterns and perceptions of complementary and alternative medicine (CAM) among leukaemia patients visiting haematology clinic of a north Indian tertiary care hospital. Pharmacoepidemiol Drug Saf. 2002;11(8):671-6. 
10. Hasan SS, Ahmed SI, Bukhari NI, Loon WC. Use of complementary and alternative medicine among patients with chronic diseases at outpatient clinics. Complement Ther Clin Pract. 2009;15(3):152-7.

11. Sharma A, Agarwal A. Complementary and alternative medicine (CAM) use among patients presenting in out-patient department at tertiary care teaching hospital in southern Rajasthan, India - a questionnaire based study. Altern Integr Med. 2015;4:1.

12. Ernst E. The role of complementary and alternative medicine. Br Med J. 2000;321:1133-5.

13. WHO traditional medicine strategy: 2014-2023. Geneva: World Health Organization; 2013 Available at http://apps.who.int/iris/handle/10665/92455. Accessed on 27 November 2013.

14. Singh V, Raidoo DM, Harries C. The prevalence, patterns of usage and people's attitude towards complementary and alternative medicine (CAM) among the Indian community in Chatsworth, South Africa. BMC Complementary and Alternative Medicine. 2004;4:3.

15. Bhalerao MS, Bolshete PM, Swar BD, Bangera TA, Kohle VR. Use of and satisfaction with complementary and alternative medicine in four chronic diseases: a cross sectional study from India. Natl Med J India. 2013;26:75-8.

16. Izzo A, Ernst E. Interactions between herbal medicines and prescribed drugs: an updated systematic review. Drugs. 2009;69:1777-98.

17. Saper RB, Phillips RS, Sehgal A, Khouri N, Davis RB, Paquin J. Lead, mercury, and arsenic in US and Indian manufactured Ayurvedic medicines sold via the Internet. JAMA. 2008;300:915-23.

18. Ernst E. Herbal medicines: balancing benefits and risks. Novartis Found Symp. 2007;282:154-67.

19. Gawde SR, Shetty YC, Pawar DB. Knowledge, attitude, and practices toward ayurvedic medicine use among allopathic resident doctors: a cross-sectional study at a tertiary care hospital in India. Perspect Clin Res. 2013;4:175-80.
20. Kunnoor NS, Rathore R, Xavier D. Physicians perception on complementary and alternative medicine (CAM): a cross sectional survey at tertiary care hospital in India. Med chem. 2015;5:197-202.

21. Furlow ML, Patel DA, Sen A, Liu JR. Physician and patient attitudes towards complementary and alternative medicine in obstetrics and gynecology. BMC Complement Altern Med. 2008;8:35.

22. Roy V, Gupta M, Ghosh RK. Perception, attitude and usage of complementary and alternative medicine among doctors and patients in a tertiary care hospital in India. Indian J Pharmacol. 2015;47(2):137-42.

23. Lewith, GT. Attitudes to and use of complementary medicine among physicians in the United Kingdom. Complementary Therapies in Medicine. 2001;9(3):167-72.

24. Zaman T, Agarwal S, Handa R. Complementary and alternative medicine use in rheumatoid arthritis: an audit of patients visiting a tertiary care centre. Natl Med J India. 2007;20:236-9.

25. Moses GM, McGuire TM. Drug interactions with complementary medicines. Aust Prescr. 2010;33:17780. Available at http://dx.doi.org/10.18773/austprescr.2010.084.

26. Eisenberg DM, Davis RB, Ettner SL, Appel S, Wilkey S, Van RompayM. Trends in alternative medicine use in the United States, 1990-1997: Results of a Follow-up National Survey. JAMA. 1998;280:1569-75.

27. Shen J, Andersen R, Albert P, Wenger N, Glaspy J, Cole $\mathrm{M}$. Use of complementary/alternative therapies by women with advanced-stage breast cancer. BMC Complementary and Alternative Medicine. 2002;2(8).

28. Thatte UM, Rege NN, Phatak SD, Dahanukar SA. The flip side of Ayurveda. (182ab). J Postgrad Med. 1993;39:179-82.

29. Garodia P, Ichikawa H, Malani N, Sethi G. Aggarwal. From ancient medicine to modern medicine: ayurvedic concepts of health and their role in inflammation and cancer. Journal of the Society for Integrative Oncology. 2007;5:1-16.

Cite this article as: Sundarmurthy D, Devarashetty V, Reddy SN. Complementary and alternative medicine: practice and perspective of allopathic doctors at a tertiary care hospital. Int J Basic Clin Pharmacol 2016;5:1995-2000. 